\title{
Experiments with in-situ thin film telephone cord buckling delamination propagation
}

\author{
Alex A. Volinsky \\ Motorola DigitalDNA ${ }^{\mathrm{TM}}$ Labs, Process and Materials Characterization Lab, \\ Tempe, AZ 85283, USA, Alex.Volinsky@ motorola.com
}

\begin{abstract}
There are many different stress relief mechanisms observed in thin films. One of the mechanisms involves film debonding from the substrate. In the case of tensile residual stress a network of through-thickness cracks forms in the film. In the case of compressive residual stress thin film buckling and debonding from the substrate in the form of blisters is observed. The buckling delamination blisters can be either straight, or form periodic buckling patterns commonly known as telephone cord delamination morphology.

The mechanics of straight-sided blisters is well understood. Current study relies on the insitu observation of phone cord delamination propagation in different thin film/substrate systems. Both straight and phone cord delaminations are shown to simultaneously propagate in the same film system. Straight-sided blisters propagate several times faster than the phone cords, and may be followed by thin film fracture along the line of maximum film buckling amplitude. Phone cord delaminations originally start as straight-sided blisters, but then deviate to the periodic phone cord geometry due to the fact that the compressive residual stress in the film is biaxial. Digital analysis of motion recordings shows that partial crack "healing" is present at the curved portions of the phone cords due to the "secondary" buckling pushing thin film back to the substrate. These experimental observations allow for the correct interpretation of the telephone cord delamination morphology.
\end{abstract}

\section{INTRODUCTION}

Stress in a thin film typically causes substrate bending. This effect is used to measure the macroscopic residual stress in thin films using Stoney's equation [1]. The residual stress can be partially relieved by plastic deformation and surface reconstruction, or simply by mechanical film failure discussed in this paper. There are many parameters that control failure mechanisms, including the sign of residual stress, properties of the film, interface and the substrate. In the case of residual tensile stress one can see film though-thickness cracking, interfacial delamination, and even substrate cracking [2]. For example, film cracking has been observed in the hybrid coatings on glass [3], and in the low-K dielectrics [4, 5]. If the film is under residual compressive stress, films typically buckle, delaminate from the substrate, and sometimes fracture by forming through-thickness cracks. In case of a thin film on a brittle substrate delamination is typically observed, whereas for the soft substrate or thick underlayer the stress is initially relieved by forming similar phone cord-like features prior to delamination (Figure 1). This paper discusses thin film interfacial failure in compression through "phone cord" delamination propagation. "Phone cords" are worm-like buckled features observed in thin films, and are called so because the they look like a twisted phone cord under the optical microscope (Figure 2). 


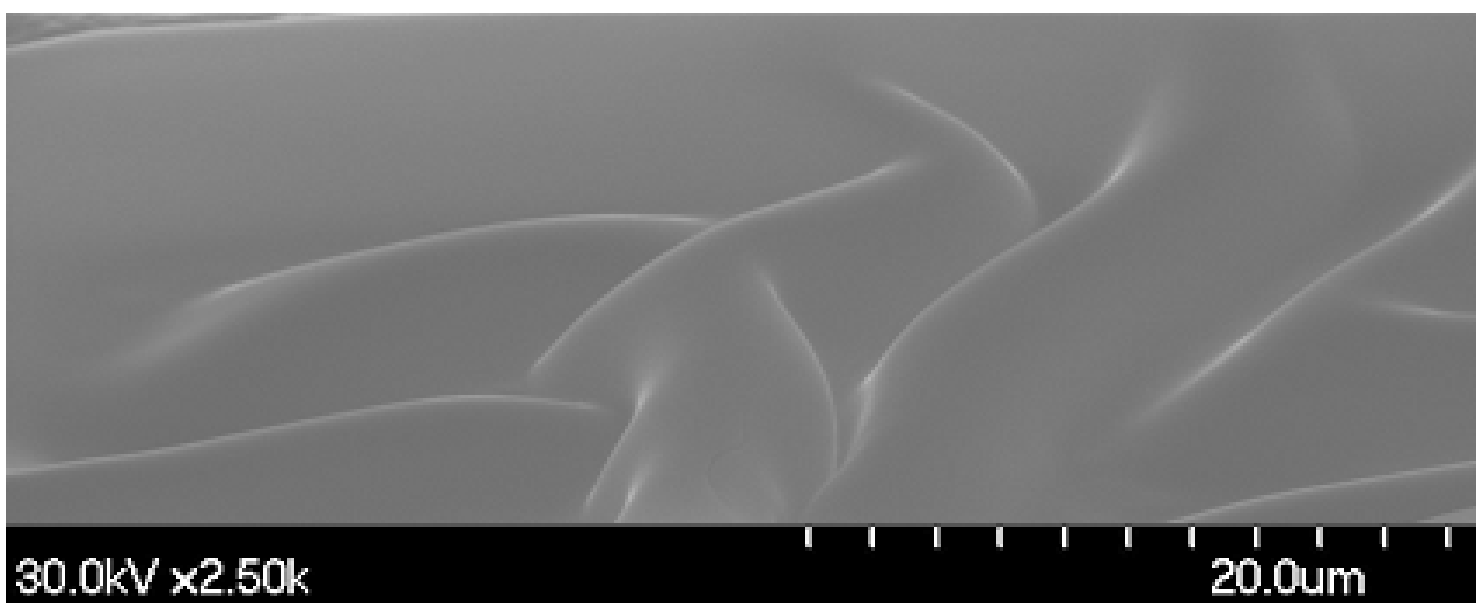

Figure 1. Phone-cord-like features found in a stiff film deposited on a compliant substrate.

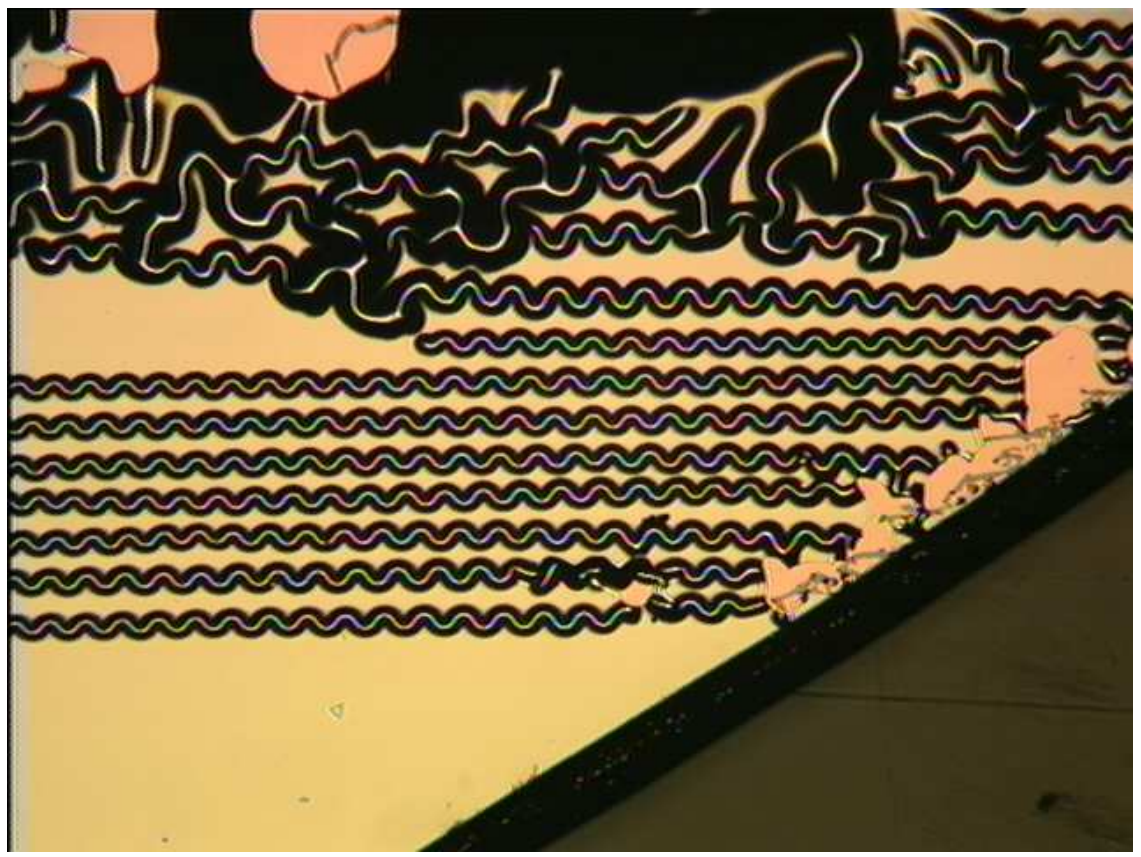

Figure 2. Phone cord buckling delamination in the low-K/TiW film system.

\section{EXPERIMENT}

The film stack has to be under residual compressive residual stress for the buckling delamination to occur. Four film systems considered in this study are: TiWxNy/GaAs, TiW/low$\mathrm{K} / \mathrm{Si}, \mathrm{W} / \mathrm{Al} / \mathrm{Si}$ and $\mathrm{W} / \mathrm{Al} / \mathrm{Cu} / \mathrm{Si}$. The $\mathrm{W}$ samples were generated by depositing a highly stressed superlayer for thin film adhesion measurements [6]. A $1 \mu \mathrm{m}$ thick $\mathrm{W}$ sputter deposited superlayer was used for $\mathrm{Al}$ and $\mathrm{Cu}$ thin films. The thinner films exhibited phone cord buckling delamination upon introducing the sputtering chamber to atmosphere after $\mathrm{W}$ deposition. A similar behavior 
was observed in the TiWxNy/GaAs [7] and TiW/low-K/Si systems due to the increased residual compressive stress. High residual compressive stress was due to the excessive amount of nitrogen in the film (Figure 3). Higher compressive stress region (1 GPa) in the bottom left corner of the wafer corresponds to the point of nitrogen introduction source.

Samples with static phone cord delaminations already present were secured on the optical microscope stage with the double-sided adhesive tape. A micromanipulator was used to further propagate delamination by applying external stress with a $\mathrm{W}$ probe needle. After inducing further delamination propagation the probe needle was removed, and the delamination blister motion was recorded in-situ with a videocassette recorder. Analog videos were later digitized using commercially available video capture board and an IBM PC computer.

\section{DISCUSSION}

Phone cord delaminations have been reported in many different thin film systems with the presence of biaxial compressive residual stress [8-12]. Straight-sided buckling-driven delaminations were also observed, especially under the influence of uniaxial external stress [1316]. Mechanics for the straight-sided blisters is well documented [17, 18]. Straight-to-phone cord transitions have been suggested to happen at a certain threshold internal stress level [19, 20]. Recent developments of Moon et al [20] determined that the phone cord morphology is possible when the straight-sided blisters become unstable at the residual stress levels exceeding the buckling stress by a factor of four.

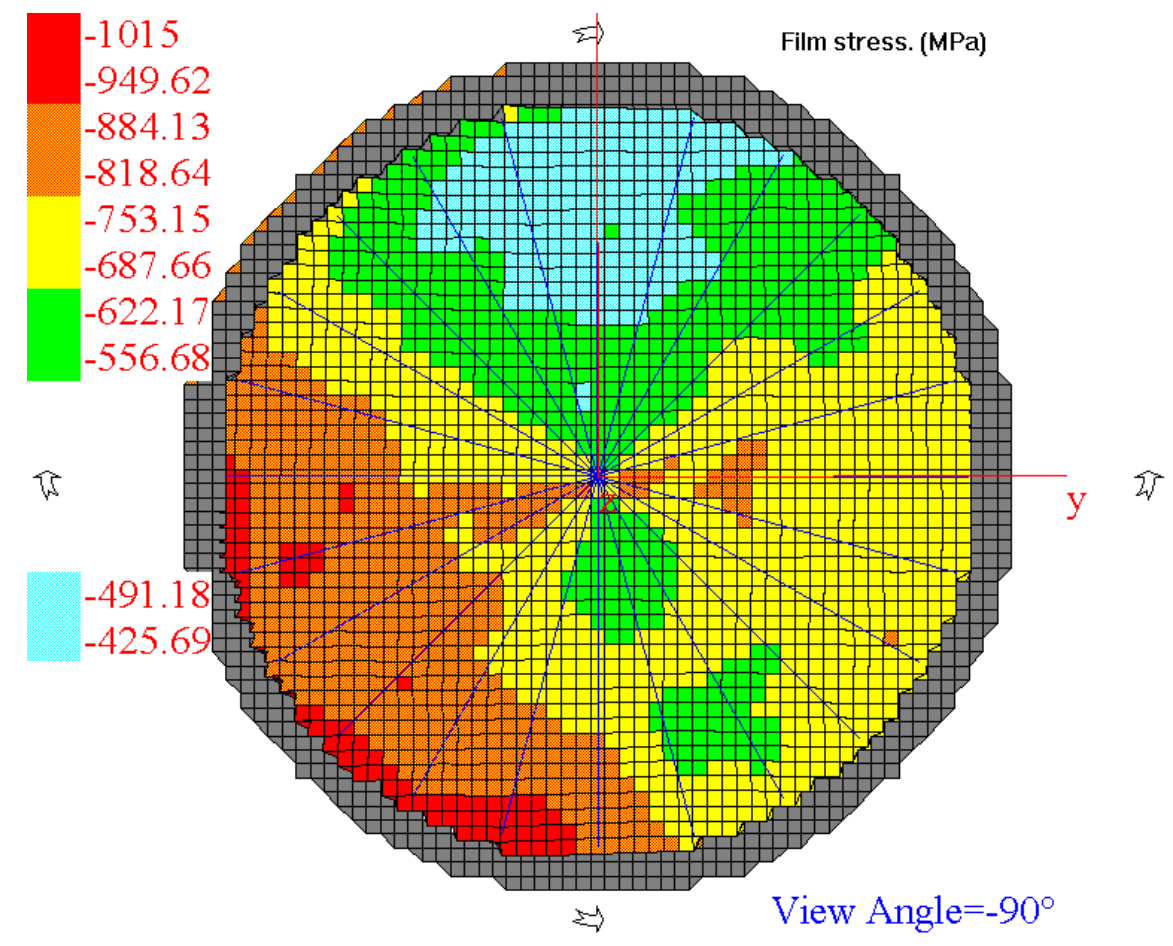

Figure 3. Residual stress map of a $1 \mu \mathrm{m}$ thick TiWxNy film on GaAs 6-inch substrate. 
In our study both phone cord and straight-sided blisters were found to exist and propagate at the same time in a TiWxNy/GaAs film system. Straight-sided blisters propagate about 10 times faster than the phone cord delaminations, and also exhibit cracking along the axis of the maximum bending stress on top of the buckle (Figure 4).

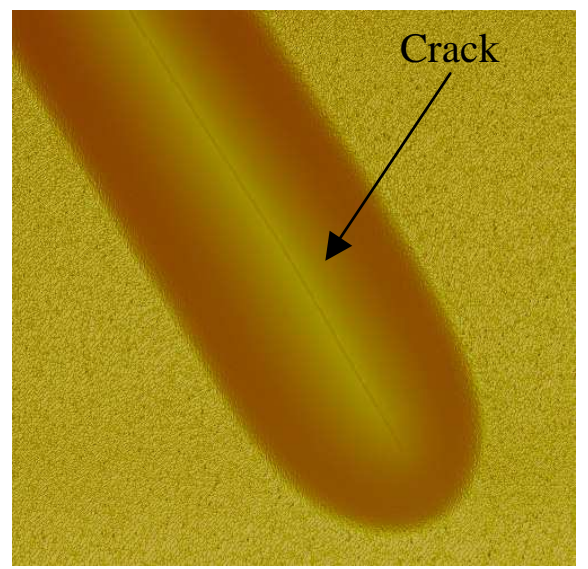

Figure 4. A 3D AFM image of a straight-sided buckling delamination exhibiting crack along the axis of the maximum bending stress. $30 \mu \mathrm{m}$ scan size.

Experimental observations of this study suggest that the phone cord dynamics is important for the straight-tophone cord transition. It was observed that phone cord delamination propagation starts out as a straight-sided blister, and then deviates to the phone-cord morphology after a certain blister length has been reached (Figure 5). In Figure 5 eight sequential contours of phone cord delamination propagation are overlaid on top of each other in order to illustrate the effects seen in video recordings of in-situ delamination propagation. There is a clear deviation from the straight blister geometry seen between the first and the fourth contours.

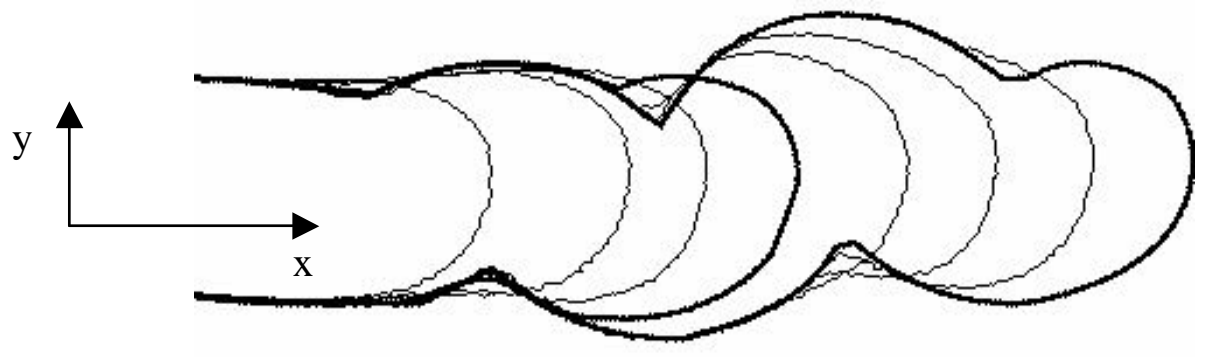

Figure 5. Eight sequential contours of phone cord delamination propagation overlaid on top of each other. Note that the blister propagates from left to right. Images were obtained by using Adobe Photoshop ${ }^{\circledR}$ trace contour filter software.

Figure 5 also shows that the already delaminated film is pressed back down to the substrate, creating and illusion that it is not delaminated (compare fourth and eighth profiles). The same behavior has been observed by Moon at al when phone cords were cross-sectioned with Focused Ion Beam (FIB) followed by AFM analysis [21]. Compared to the final profile of the telephone cord, it is effectively a larger area of the film that is delaminated. This is the main experimental result of this work.

Crack dynamics becomes very important for understanding the phone cord morphology. The stress state of the originally straight-sided blister is given by

$$
\sigma_{x x}=-\left[v \sigma_{B}+(1-v) \sigma_{R}\right] \text { and } \sigma_{y y}=-\sigma_{B}=-\frac{\pi^{2}}{12} \frac{E}{\left(1-v^{2}\right)}\left(\frac{h}{b}\right)^{2}
$$


where $\sigma_{R}$ is the biaxial residual stress in the film, $\sigma_{B}$ is the buckling stress, $h$ is the film thickness, and $b$ is the half width of the straight blister. While the buckling stress is small (100 MPa for a $0.3 \mu \mathrm{m}$ thick TiWxNy film), the $\sigma_{x x}$ stress is quite large ( $1 \mathrm{GPa}$ for the same TiWxNy film). It is the $\sigma_{x x}$ stress that drives the blister growth in the x direction. There would be no phone cord transition if the straight blister front were to propagate at a high enough speed, relieving the $\sigma_{x x}$ stress. On the contrary, if the crack front velocity is not high enough, "secondary" blister buckling occurs along the $x$ axis due to the $\sigma_{x x}$ stress, causing delamination to propagate sideways, and "healing" on the opposite side. Theoretical interpretation of the "secondary antisymmetric" buckling phenomenon is given by Audoly [22]. In our case both straight and phone-cords delaminations are present in the same TiWxNy film due to the fact that the straight blisters crack on top, which provides another mechanism for the stored elastic energy to be released.

In conclusion, the importance of biaxial stress is demonstrated. Having a metallic film on the top and transparent substrate on the bottom, a regular recordable compact disk (CDR media) appears to be a perfect model system for studying buckling delamination. One can carry out an experiment, in which pressing a needle into the upper side of the compact disk (CD) creates a precrack. Bending the CD imposes compressive stress $\left(\sigma_{x x}\right)$ on the upper film, which results in a straight buckling delamination (Figure 6a). Bending the same CD in the perpendicular direction $\left(\sigma_{y y}\right)$ causes the straight blister in Figure 6a to produce a "secondary" buckle, which appears as a wavy pattern. Phone cord morphology would only be possible if both $\sigma_{x x}$ and $\sigma_{x x}$ are imposed simultaneously.
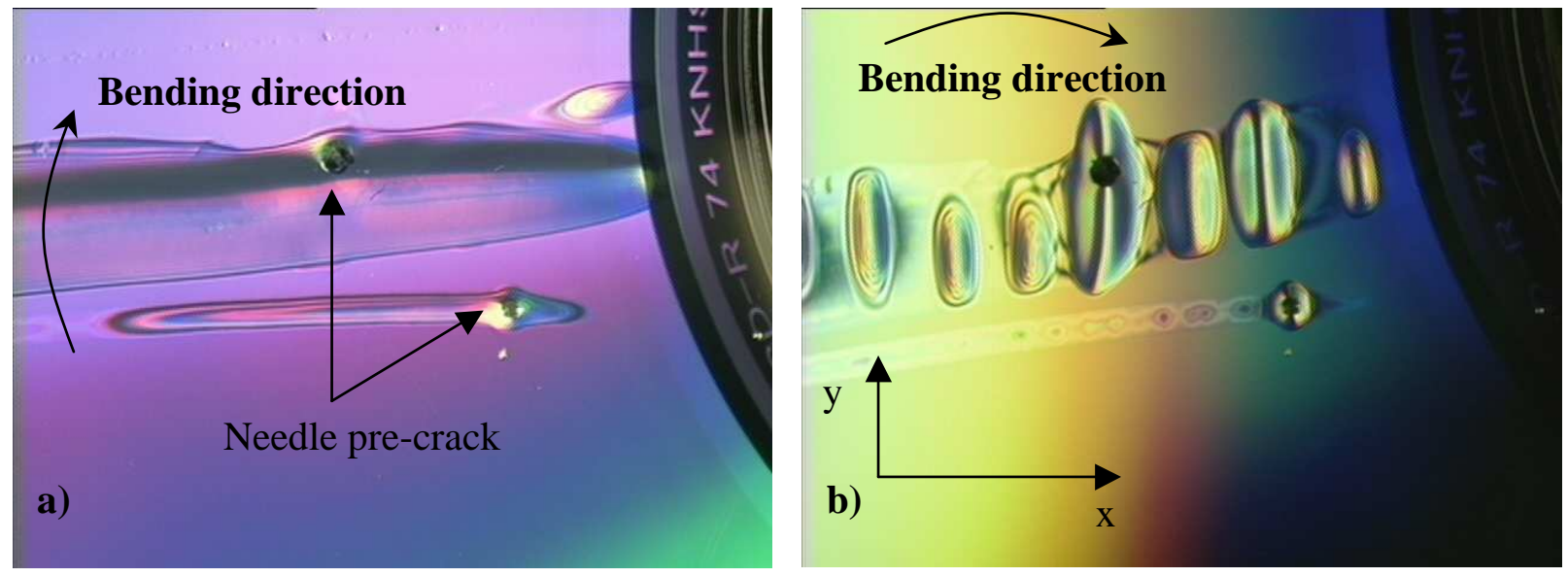

Figure 6. a) Straight-sided blisters seen from the bottom of a CD under bending; b) Periodic buckling of the straight-sided blisters in a) when bending stress is applied in the perpendicular direction.

\section{CONCLUSIONS}

For the practical applications in order to avoid thin film buckling delamination, one has to decrease the amount of residual stress in the film, and/or decrease the film thickness. 
There are three characteristic conditions for the telephone cord blister morphology to exist: 1) biaxial residual stress; 2) the level of the stress has to exceed the film buckling stress by a factor of 4 [21]; 3) blister front propagation should be slow enough, so that there is no cracking at the top of the blister [23].

\section{ACKNOWLEDGEMENTS}

The author would like to thank William W. Gerberich, Neville R. Moody, John W. Hutchinson and David F. Bahr for valuable discussions, and Xiang-Dong Wang and Epiphany A. Irwin for AFM analysis.

\section{REFERENCES}

1. G.G. Stoney, Proc.Roy.Soc.Lond. A82, 72 (1909)

2. M.D. Thouless, J. Vac. Sci. Technol. A 9(4), 2510-2515, (1991)

3. J. Malzbender, G. de With, Thin Solid films 359, 210-214, (2000)

4. A.A. Volinsky, J.B. Vella, W.W. Gerberich, accepted in Thin Solid Films, (2002)

5. J. B. Vella, I. S. Adhihetty, K. Junker, A. A. Volinsky, accepted in International Journal of Fracture, (2002)

6. A.A. Volinsky, N.R. Moody, W.W. Gerberich, Acta Mater. 50(3), pp. 441-466, 2002

7. A.A. Volinsky, N.R. Moody, M.L. Kottke, W.W. Gerberich, Philosophical Magazine A, 82, 2002

8. N. Matuda, S. Baba, A. Kinbara, Thin Solid Films 81, 301, (1981)

9. G. Gille, B. Rau, Thin Solid films 120, 109-121, (1984)

10. J. Seth, R. Raghunath, S.V. Babu, J. Vac. Sci. Technol. A 10(2), (1992)

11. H.Y. Yu, C. Kim, C. Sanday, Thin Solid films 196, 229-233, (1991)

12. D. He, W. Cheng, J. Qin, J. Yue, E. Xie, G. Chen, Appl. Surf. Sci., 191, 338, (2002)

13. C. Coupeau, J.F. Naud, F. Cleymand, P. Goudeau, J. Grilhé, Thin Solid Films 353, 194-200, (1999)

14. B. Cotterell, Z. Chen, Key Eng. Mater. 183-187, 187-192, (2000)

15. B. Cotterell, Z. Chen, Int. J. of Fractrure, 104, 169-179, (2000)

16. F. Cleymand, C. Coupeau, J. Grilhé, Scripta mater. 44, 2623-2627, (2001)

17. H.M. Jensen, Acta mater. 41(2), 601-607, (1993)

18. H.M. Jensen, I. Sheinman, Int. J. of Fracture 110, 371-385, (2001)

19. M. Ortiz, G. Gioia, J. Mech. Phys. Solids 42(3), 531, (1997)

20. K.M Crosby, R.M. Bradley, Phys. Rev. E 59(3), 2542-2545, (1999)

21. M.-W. Moon, H.M. Jensen, J.W. Hutchinson, K.H. Oh, A.G. Evans, J. Mech. Phys Solids, 50(11), 2355, (2002)

22. B. Audoly, Phys. Rev. Let., 83, 4124, (1999)

23. A.A. Volinsky et al, to be published 